\title{
Suprapubic Cystostomy Site Incisional Hernia: A Complication of Suprapubic
}

\section{Catheter Placement}

\author{
Samarth Agarwal", Manoj Kumar, Deepanshu Sharma and Satya Narayan Sankhwar \\ Department of Urology, King George's Medical University, Lucknow, India
}

*Corresponding author: Agarwal S, Department of Urology, King George's Medical University, Lucknow, India, Tel: +919415007703; E-mail: rebellite@ gmail.com

Received: March 13, 2018; Accepted: March 20, 2019; Published: March 25, 2019

\begin{abstract}
Supra-pubic Catheterisation (SPC) is one of the commonly done Urological Procedures. Certain long term complications of Suprapubic catheter have been commonly reported like urinary tract infections, catheter blockage due to debris, suprapubic pain and haematuria. However immediate and intermediate complications are rarely reported. Incisional herniation through the SPC site is not uncommon and can present early. Diagnosis is mostly clinical and straightforward. Hernias through SPC site should be repaired early owing to complications of strangulation, incarceration and small bowel obstruction if left untreated as the neck is narrow. A prompt surgical intervention should be the normal dictum in such patients to prevent life-threatening complications.
\end{abstract}

\section{Background}

Suprapubic Catheterisation (SPC) is one of the commonly done Urological Procedures. Advantages of Suprapubic Catheterisation Over Transurethral Catheterisation have been systematically laid by Hunter et al in their review and are Plentiful including Increased Patient Comfort, Low risk Of infections and improved quality of life [1].

However, like transurethral catheterization, certain long term complications of Suprapubic catheter have been reported like urinary tract infections, catheter blockage due to debris, suprapubic pain and haematuria. We report an extremely rare case of suprapubic site incisional hernia in a young male which was surgically corrected with mesh placement.

\section{Case Presentation}

A 40 year old male patient presented with complaints of acute urinary retention. He had multiple failed attempts of Perurethral catheter placement in last 1 week and was bleeding per-urethrally therefore we decided to place a suprapubic catheter. He had no operative history in the past.

Citation: Agarwal S, Kumar M, Sharma D, et al. Suprapubic Cystostomy Site Incisional Hernia: A Complication of Suprapubic Catheter Placement. Clin Case Rep Open Access. 2019;2(1):122. 
A small incision (around $1 \mathrm{~cm}$ in length) was taken $2 \mathrm{~cm}$ above the pubic symphysis in the midline and distended bladder was entered using trocar and cannula under ultrasound guidance as shown in the FIG. 1.

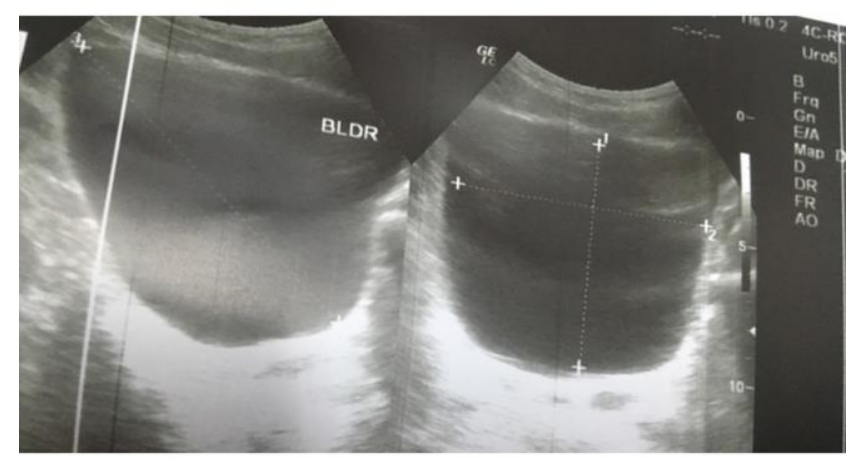

FIG. 1. Distended urinary bladder.

A 16 Fr Foley catheter was placed as shown in FIG. 2 and tapped to the abdomen at the end of the procedure. Patient was then asked to follow up in the out-patient department.

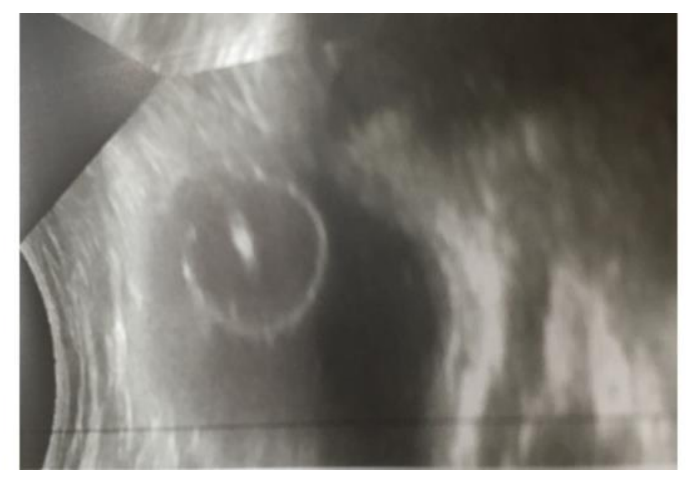

FIG. 2. 16fr catheter placed suprapubically via ultrasound guidance and tapped to the abdomen.

Patient then presented to us after 1 month with complaints of swelling in the lower part of abdomen. On physical and abdominal examination he was found to have a $4 \times 5 \mathrm{~cm}$ size reducible swelling at cystostomy site with positive cough impulse with suprapubic catheter in situ as shown in the FIG. 3 and 4. The swelling could be manually reduced. There was no pain or tenderness.

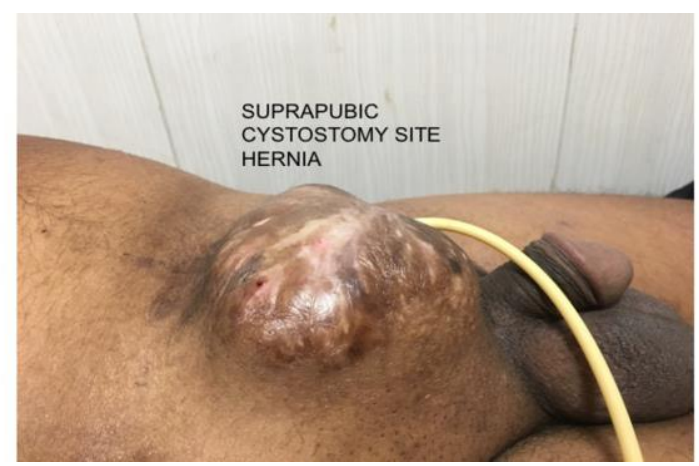

FIG. 3. Suprapubic cystostomy site showing Hernia. 


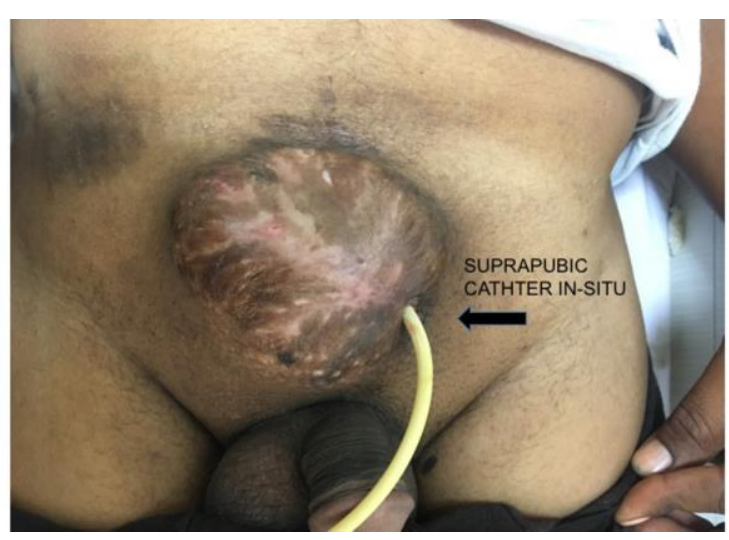

FIG. 4. Suprapubic hernial site with cathter In Situ.

\section{Conclusion}

Incisional hernia should be kept in mind in patients with suprapubic catheterization and complaint of lower abdominal pain/swelling. A prompt surgical intervention should be the normal dictum in such patients to prevent bowel strangulation, rupture and other life-threatening complications.

\section{Investigations}

On further imaging by Ultrasound, a small defect of around $2 \mathrm{~cm}$ size at SPC site was seen with reducible herniation of bowel contents.

On further evaluation with retrograde urethrogram (RGU) he was also found to have a short segment Peno-bulbar urethral stricture for which optical internal urethrotomy (OIU) was performed and 16 Fr per-urethral catheter was placed.

\section{Differential Diagnosis}

\subsection{Treatment}

We then performed an anatomical repair of the suprapubic site hernia using prolene mesh to avoid common yet lifethreatening complications of untreated hernia like strangulation and/or obstruction.

At surgery, a $2 \mathrm{~cm}-3 \mathrm{~cm}$ defect was noticed around the catheter in the linea alba. The hernial sac was isolated and excised, the neck was found to be narrow. The fascial edges surrounding the defect were trimmed and closed with a running suture of 0 polydioxanone and reinforced with a small prolene mesh using overlay technique.

\section{Outcome and Follow-up}

At 3 months follow-up post operatively the patient was voiding well with no evidence to prove recurrence of Hernia. 
www.yumedtext.com | March-2019

\section{Discussion}

Suprapubic catheterisation is amongst the commonly performed urological procedure done for urinary diversion. A number of complications have been reported following SPC insertion like small bowel perforation, bleeding, urinary tract infections, calculus formation and bladder spasms/irritation [2-4].

Incisional herniation through the SPC site is a rare but important complication. The exact mechanism is speculative yet a description is given by Nabi et al of SPC hernia following catheter removal. They described that catheter removal leads to herniation of peritoneum and abdominal contents with progressive herniation leading to enlargement of hernia sac and defect. Once the bladder decompresses it provides opportunity for peritoneal contents to herniate in potential weakness of trocar site [5].

However, our case is unique that the hernia presented with suprapubic catheter in-situ. Infact, a thorough such of literature revealed only a single similar case scenario reported previously by AR Rao et al. They reported a 72yr old male patient who developed SPC site hernia (while SPC was in-situ) which was placed for a contractile bladder [6].

Till 2008 only 6 cases have been reported in literature [7].

Hernias through SPC site should be repaired early owing to complications of strangulation, incarceration and small bowel obstruction as the neck is narrow. All attempts should be made to perform trocar-cannula SPC at a lower level in a distended bladder.

This is only the second case of SPC site hernia reported in literature with SPC in-situ. A urologist must be aware of this important complication following suprapubic catheter placement.

\section{Learning Points/Take Home Messages}

- Suprapubic cystostomy site Incisional Hernia is a rare but important complication.

- All attempts should be made to perform trocar-cannula SPC at a lower level in a distended bladder.

- A urologist must be aware of this complication.

- Prompt surgical treatment is not only $100 \%$ curative but also prevents life -threatening complications.

\section{REFERENCES}

1. Hunter KF, Bharmal A, Moore KN. Long-term bladder drainage: Suprapubic catheter versus other methods: a scoping review. Neurourol Urodyn. 2013;32(7):944-51.

2. Mongiu AK, Helfand BT, Kielb SJ. Small bowel perforation during suprapubic tube exchange. Can J Urol. 2009;16(1):4519-21.

3. Noller KL, Pratt JH, Symmonds RE. Bowel perforation with suprapubic cystostomy. Report of two cases. Obstet Gynecol. 1976;48(1):67S-9S. 
www.yumedtext.com | March-2019

4. Borrero GO, Miller PR, Vora K, et al. Acute ureteral obstruction as a complication of suprapubic catheterization. Urol Radiol. 1987;9(3):171-3.

5. Nabi G, Aron M, Gupta NP. Incisional hernia after suprapubic trocar cystostomy. Urol Int. 2003;70(3):249-50

6. Rao AR, Hanchanale VS, Sharma M, et al. Incisional hernia around the suprapubic catheter: an unusual complication. Hernia. 2007;11(1):61-2.

7. Liu DS. Incarcerated hernia around a suprapubic catheter. ANZ J Surg. 2012;82(10):762-3. 